\title{
Investigation of strain measurements in (curved) wide plate specimens using digital image correlation and finite element analysis
}

\author{
Stijn Hertelé', Wim de Waele ${ }^{2}$, Rudi Denys ${ }^{2}$ and Matthias Verstraete ${ }^{2}$
}

\begin{abstract}
Some pipelines face global plastic straining due to the nature of their installation process or harsh environmental conditions during operation. The ability of the girth welds to withstand these plastic strains is often evaluated on the basis of wide plate tests. Key for the validity of these tests is a representative measurement of remote strain, mostly obtained by linear variable differential transformers and/or strain gauges. The outcome of the remote strain measurement depends on the specimen geometry and the position of these sensors. In an attempt to investigate a specific geometric design of wide plate specimens and to find appropriate remote strain sensor positions, the authors have performed a series of tension tests on medium-sized wide plate specimens, supported by digital image correlation strain measurements. In addition, finite element simulations have been performed to evaluate whether the experimental observations can be extrapolated to a wider range of conditions. The results indicate that the strain distribution is mostly influenced by the weld strength mismatch, which governs the lateral restraint. For all experiments and simulations, nevertheless, the strain field was highly uniform in an identified zone, resulting in simple guidelines regarding specimen geometry and sensor positioning.
\end{abstract}

\section{Keywords}

Pipeline, wide plate test, remote strain, digital image correlation, finite element analysis

Date received: 21 December 201 I; accepted: 16 March 2012

\section{Introduction}

Facing the fact that existing fossil energy resources exhaust, new oil and gas fields have to be exploited in increasingly hostile environments. A challenging installation (e.g. reeling in offshore applications) or the presence of geological phenomena during operation (e.g. landslides or earthquakes) may cause the involved transmission pipelines to deform plastically. In such cases, displacements are imposed rather than loads and a so-called strain-based design is required to ensure structural integrity. Critical locations are the girth welds that connect different pipe sections, due to the likely presence of weld flaws and microstructures with reduced mechanical properties.

For pipelines that have to withstand global plastic deformations, a widely validated and standardized procedure for the assessment of girth weld flaws is inexistent $^{1,2}$ and an extensive testing program remains essential for the qualification of pipe and weld design. Typically involved is the curved wide plate (CWP) tension test, which can be described as an intermediatescale tensile test on an unflattened sample of a pipeline section containing a girth weld (Figure 1(a)). A circumferential weld flaw is often deliberately introduced by means of a machined notch. End blocks are welded to the specimen to enable mounting it into a test rig. This implicates the need for end shoulders to obtain a gradual transfer of load to the prismatic part of the specimen, which contains the girth weld (Figure 1(b)). All geometrical parameters are introduced in Figure 1(c). CWP tension tests can be considered as a variant to conventional (flat) wide plate (WP) tension testing, as first reported in 1944 for the fracture analysis of ship

'FWO Flanders aspirant, Ghent University, Belgium

${ }^{2}$ Laboratory Soete, Ghent University, Belgium

\section{Corresponding author:}

Stijn Hertelé, FWO Flanders aspirant, Ghent University, Laboratory Soete, Technologiepark Zwijnaarde 903, 9052 Zwijnaarde, Belgium. Email: stijn.hertele@ugent.be 


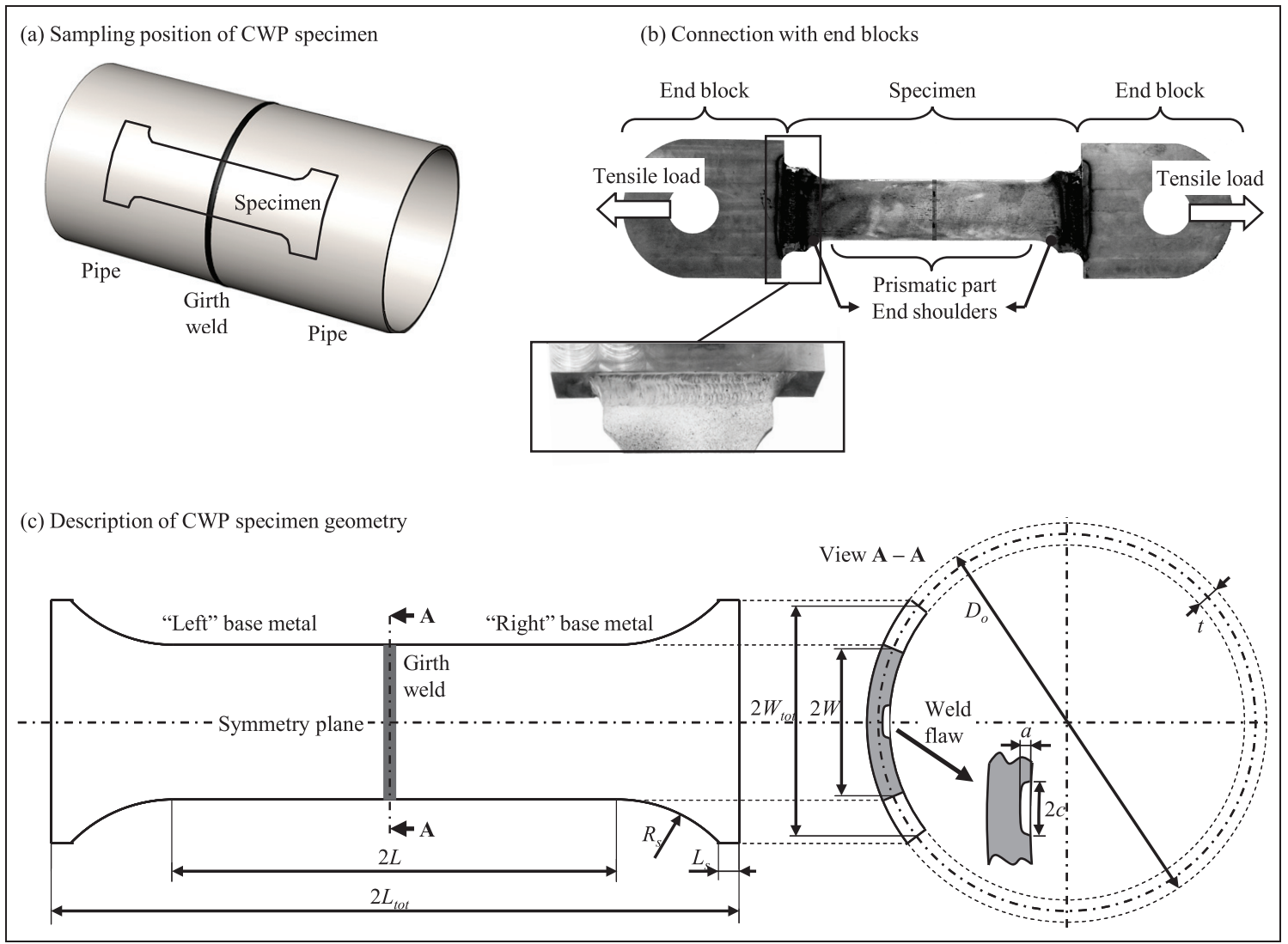

Figure I. Description of a CWP specimen, introducing geometrical characteristics.

plates. ${ }^{3}$ Nevertheless, some additional issues arise over more traditional linear-elastic investigations due to the introduction of global plastic deformations. In particular, the CWP test is aimed at giving a proper representation of the effect of an in-the-field pipeline girth weld flaw including possible effects of strength heterogeneity between two welded plates and weld strength mismatch. Noteworthy hereby is that the flaw tip constraint (Q-stress) in a CWP specimen is highly similar to that in a girth weld of a pressurized pipe. ${ }^{4,5}$

The principal result of a (C)WP test for a strainbased assessment is the relation between crack driving force and the remotely applied longitudinal strain (further called 'remote strain'), whose proper measurement is key to obtaining a valid test result. Note that remote strain can significantly differ between both welded plates due to the abovementioned plate-to-plate heterogeneity in terms of yield strength and/or post-yield behaviour. Crack driving force is typically estimated by a clip gauge which traverses the weld flaw and measures the crack mouth opening displacement. Remote strains are obtained from strain measurements in both base plates, usually by means of strain gauges and/or linear variable differential transformers (LVDTs). Recently, more advanced full field strain measurement techniques such as optical photoelasticity and digital image correlation have been reported to visualize the entire surface strain distribution in a CWP specimen. ${ }^{6,7}$ Earlier, similar digital image correlation measurements have been performed on wide centre-notched thin aluminium panels. ${ }^{8,9}$

Whereas a (C)WP specimen is restricted in length due to test rig limitations, it aims at representing a long pipeline section. Saint Venant's principle implicates that, when loaded in tension, the longitudinal strain field in a section at a considerable distance from the girth weld is uniform. Hence, for the CWP specimen to be representative, it should ideally contain two areas of uniform longitudinal strain (one at each side of the weld). In such case, the strain distribution near the flawed weld is no longer influenced by the specimen's end shoulders and their connection to end blocks. Additionally, if the remote strain measurements at both sides are performed within this area, an unambiguous test result is achieved. Hence, the occurrence of areas of uniform longitudinal strain (but possibly different at both sides of the weld) strongly improves the representativeness and exchangeability of the test result.

To achieve a zone of uniform longitudinal strain in a CWP specimen, recent studies advise a prismatic length-to-width ratio $2 L / 2 W$ (or $L / W$ ) of at least $3 .^{10-12}$ This is more than the minimum $L / W$-ratio of 2 specified in the ASTM-standard E740 ${ }^{13}$ for wide plate tests intended for stress-based fracture investigation (thereby focussing on applied load rather than remote strain). Nevertheless, since the (C)WP test is not yet standardized for use in strain-based design and since its dimensions are mostly restricted by test rig limitations, many 
Table I. Overview of published wide plate specimen geometries with analysis on the basis of strain measurements (ordered by increasing L/W-ratio).

\begin{tabular}{|c|c|c|c|}
\hline Author (year) & $\begin{array}{l}2 L \\
(\mathrm{~mm})\end{array}$ & $\begin{array}{l}2 \mathrm{~W} \\
(\mathrm{~mm})\end{array}$ & $\begin{array}{l}\text { L/W } \\
(-)\end{array}$ \\
\hline Minami et al. $(1995,201 \mathrm{I})^{14,15}$ & 300 & 400 & 0.75 \\
\hline Motarjemi $(2009)^{16}$ & 50 & 50 & 1.00 \\
\hline $\begin{array}{l}\text { Ishikawa et al. (2004) } \\
\text { Igi and Suzuki }(2007)^{18}\end{array}$ & 300 & 200 & 1.50 \\
\hline Denys $(1990)^{19}$ & 550 & 300 & 1.83 \\
\hline Igi et al. $(20 \mid 0)^{20}$ & 600 & 200 & 3.00 \\
\hline Igi et al. $(2008)^{21}$ & 900 & 300 & 3.00 \\
\hline \multicolumn{4}{|l|}{ Denys and Lefevre $(2009)^{22}$} \\
\hline Fairchild et al. (2008) & 1000 & 300 & 3.33 \\
\hline Richards et al. $(2010)^{23}$ & 1016 & 254 & 4.00 \\
\hline Stephens et al. $(2009,2010)^{24,25}$ & 1028 & 229 & 4.50 \\
\hline
\end{tabular}

different geometrical designs have been applied with $L / W$-ratios ranging from 0.75 to $4.50^{11,14-25}$ (Table 1 ; to the authors' knowledge). Note that the specimens adopted in Motarjemi ${ }^{16}$ were only $50 \mathrm{~mm}$ wide, which is small compared to common (C)WP tests. Nevertheless, they have been included in the table because their purpose was also to investigate the crack driving force response in a strain-based design context. Apart from Table 1, other studies have reported (C)WP tests without mentioning the specimen geometry. ${ }^{26,27}$

Considering the above, (C)WP specimen geometry and the positions of remote strain sensors should be consciously considered prior to performing an experimental program. This paper summarizes a feasibility study of a new specimen design, summarized in Table 2 , based on experimentally validated finite element results. The specimen width $2 W$ in this design has been chosen $150 \mathrm{~mm}$ to limit the required tensile force to values below $2500 \mathrm{kN}$. Note that the $L / W$-ratio is 3.33 , which satisfies the guidance from Wang et al. ${ }^{10}$ Fairchild et al., ${ }^{11}$ and Hertelé et al. ${ }^{12}$ The second section provides the analysis methodology applied for both experiments and finite element simulations. The third and fourth sections elaborate the experimental and finite element simulation program, respectively. The fifth section discusses the results and the sixth provides conclusions.

\section{Analysis method}

As briefly mentioned in the introduction, this paper mostly reports on the results of a finite element study.
This allows for the variation of a deliberate set of parameters over desired ranges, which would be unpractical solely on the basis of experiments. In addition, a set of three experiments is reported to serve as a validation of the finite element results.

Both the presence of a zone of uniform longitudinal strain and the effect of remote strain sensor location have been analyzed. The applied method is equivalent for both finite element simulations and experiments and explained in the following. First, the uniformity of longitudinal strains has been investigated at different cross sections in the prismatic part of the specimen. Introducing a $z_{45}$-coordinate which is zero where 45 degree lines starting from the flaw centre intersect the specimen edges, these sections are characterized by: $z_{45^{\circ}}=0,25,50,75$ and $100 \mathrm{~mm}$ (Figure 2). The area closer to the flaw $\left(z_{45^{\circ}}<0 \mathrm{~mm}\right)$ is considered to show a non-uniform strain distribution due to shear lines theoretically originating from the flaw at 45 degrees. The area further from the flaw $\left(z_{45^{\circ}}>100 \mathrm{~mm}\right)$ is also assumed to strain non-uniformly due to the vicinity of the specimen shoulders. The validity of these statements is discussed in the fifth section.

Since sub-surface strains cannot be readily observed experimentally, the analysis of each cross section has been confined to its intersection with one of the two specimen surfaces (further referred to as a 'path'). This simplification is built upon the assumption that, under pure tension, the strain distribution is uniform in the through-thickness direction. For each investigated path, the strain uniformity is further quantified by a dimensionless coefficient of variance $c_{v}$. It is defined as the standard deviation of longitudinal strain over the path divided by the average longitudinal strain.

As deformation develops in the specimen during the test, $c_{v}$ may be prone to changes. To obtain one single output value for every path, $c_{v}$ is averaged over the test progress as follows

$$
\overline{c_{v}}=\frac{\int_{\varepsilon_{i}}^{\varepsilon_{f}}\left|c_{v}\right| \mathrm{d} \varepsilon}{\varepsilon_{f}-\varepsilon_{i}} \geqslant 0
$$

where $\varepsilon_{i}$ and $\varepsilon_{f}$ are the longitudinal strains (averaged over the considered path) at the beginning and the end of a considered period, respectively. If the entire test is considered, $\varepsilon_{i}$ is zero and $\varepsilon_{f}$ the failure strain (often arbitrarily defined as the strain that corresponds with maximum load). The path with the lowest $\overline{c_{v}}$-value is interpreted as having the most uniform longitudinal

Table 2. Investigated specimen geometry.

\begin{tabular}{llllll}
\hline $\begin{array}{l}\text { Prismatic length } \\
2 L(\mathrm{~mm})\end{array}$ & $\begin{array}{l}\text { Prismatic width } \\
2 \mathrm{~W}(\mathrm{~mm})\end{array}$ & $\begin{array}{l}\text { Total length } \\
2 L_{\text {tot }}(\mathrm{mm})\end{array}$ & $\begin{array}{l}\text { Total width } \\
2 \mathrm{~W}_{\text {tot }}(\mathrm{mm})\end{array}$ & $\begin{array}{l}\text { Shoulder radius } \\
R_{s}(\mathrm{~mm})\end{array}$ & $\begin{array}{l}\text { Shoulder } \\
\text { runout length } \\
L_{s}(\mathrm{~mm})\end{array}$ \\
\hline 500 & 150 & 700 & 210 & 75 & 40 \\
\hline
\end{tabular}




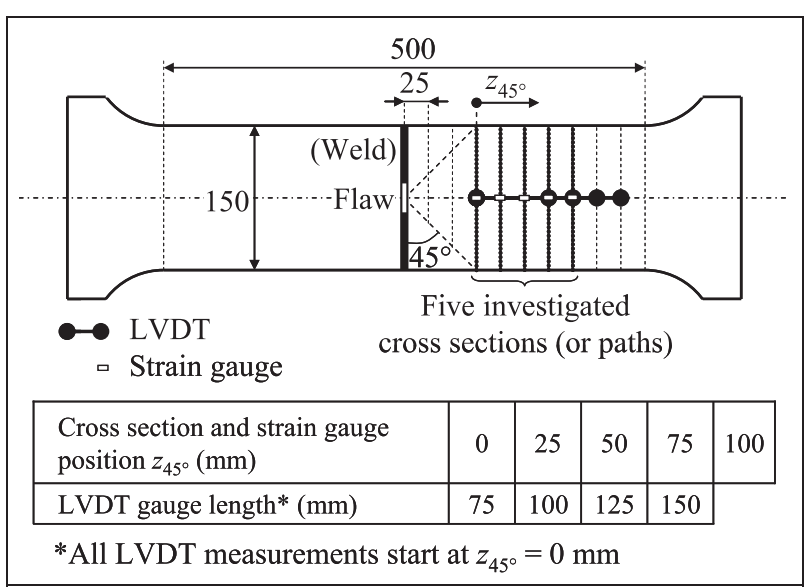

Figure 2. Strain distributions have been investigated at five cross sections, and four LVDT mounting positions have been considered.

LVDT: linear variable differential transformer.

strain distribution (the extreme case of a fully uniform strain field corresponding with $\overline{c_{v}}=0$ ). The average strain observed over that path is considered as the best possible measure of remote strain. It is further seen as a reference for other strain measurements and is denoted as $\varepsilon_{r, r e f}$.

Second, to quantify the ability of a sensor to measure remote strain, its measurement $\varepsilon_{r \text {,meas }}$ is compared to the reference measurement $\varepsilon_{r, r e f}$. Both local strain measurements (e.g. using strain gauges) and measurements covering a wider area (using LVDTs) have been investigated. Ideally, the ratio $\varepsilon_{r, \text { meas }} / \varepsilon_{r, \text { ref }}$ should approximate unity during the full course of the test. Hereby, it is important to compare equal formulations of strain. For this paper, all strains are expressed as a logarithmic strain (also known as 'true strain' or 'Hencky strain'). For the LVDT measurements, $\varepsilon_{r \text {, meas }}$ has been obtained from the gauge length extension $\Delta G L$ and the initial gauge length $G L_{0}$ as follows

$$
\varepsilon_{r, \text { meas }}=\ln \left(1+\frac{\Delta G L}{G L_{0}}\right)
$$

In total, four LVDT positions have been considered (Figure 2). Note that some LVDTs exceed the assumed potential area of uniform strain $\left(0 \mathrm{~mm}<z_{45^{\circ}}<\right.$ $100 \mathrm{~mm}$ ). Longer LVDTs have also been considered since they produce signals with a lower relative measurement error, due to the denominator $G L_{0}$ in equation (2). In the absence of other considerations, they are therefore preferred over smaller LVDTs.

\section{Experimental study}

\section{Material}

To experimentally investigate the proposed geometrical design, three (curved) wide plate tests (WP1, WP2, WP3) have been performed and analyzed. Next to the geometry from Table 2, supplementary information is given in Table 3. WP1 and WP2 have been taken from the same flat plate and do not contain a weld. As a consequence, 'left' and 'right' base metal are equal. WP1 and WP2 only differ in flaw length. Also, WP2 was ended prior to failure. Nevertheless, a remote

Table 3. Characteristics of the performed (curved) wide plate tests.

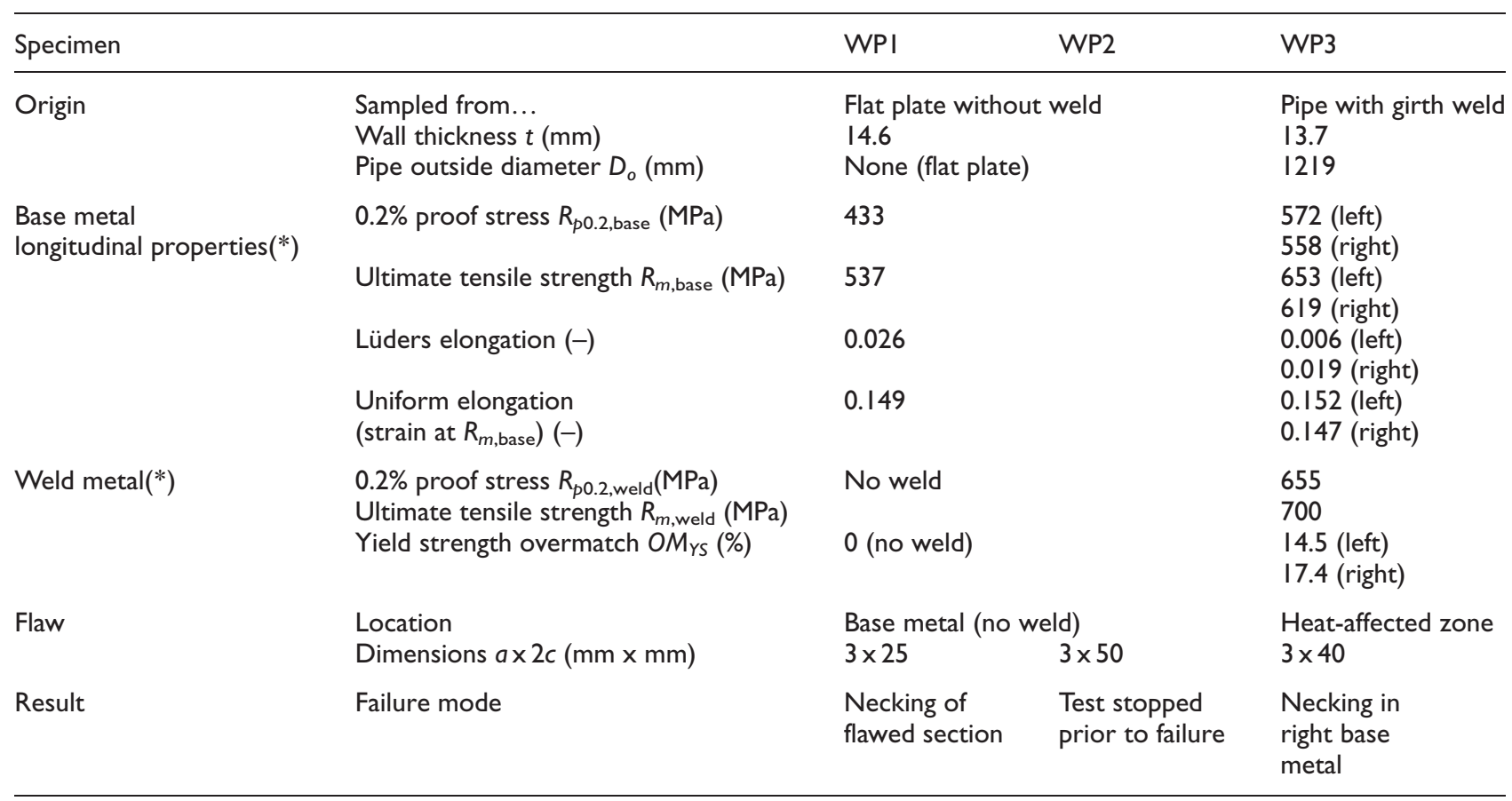

(*) All strength and ductility characteristics have been derived from engineering stress-strain diagrams, obtained from small-scale tensile tests. Strains have been converted to logarithmic values. Reported values represent averages of two tests. 


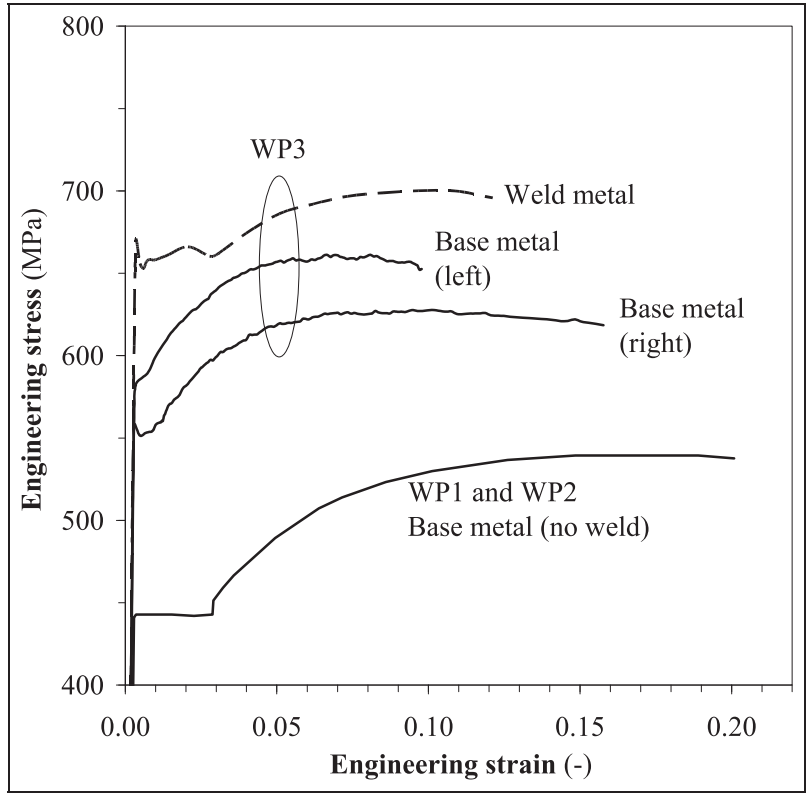

Figure 3. Stress-strain curves of the experimentally tested materials.

strain of $8 \%$ was achieved, which is sufficient to allow for an extensive analysis. In contrast to WP1 and WP2, WP3 has been sampled from a pipeline and is therefore curved. It contains a girth weld. All base metals exhibit a discontinuous yielding behaviour with a Lüders plateau, most pronounced for WP1 and WP2. The weld in WP3 is significantly stronger than the involved base metals, which is reflected in the yield strength overmatch, $O M_{Y S}$, defined as $\left(R_{p 0.2}\right.$ is the $0.2 \%$ proof stress):

$$
O M_{Y S}=\left(\frac{R_{p 0.2, \text { weld }}-R_{p 0.2, \text { base }}}{R_{p 0.2, \text { base }}}\right) \cdot 100 \%
$$

Apart from the strength mismatch between base and weld metal, WP3 is additionally characterized by a strong heterogeneity between the two base metals. This is reflected in the differences in $0.2 \%$ proof stress and ultimate tensile strength between the 'left' and the 'right' base metal.

By means of illustration, Figure 3 shows representative stress-strain curves for all involved materials: base metal of WP1 and WP2 (one curve), base metals for WP3 (one curve for each plate) and weld metal for WP3.

\section{Instrumentation for measurement of remote strain}

Apart from equipping the wide plate specimens at one surface with two LVDTs (one at each side from the flaw; end points at $z_{45^{\circ}}=0 \mathrm{~mm}$ and $z_{45^{\circ}}=100 \mathrm{~mm}$ ) for measurements of remote strain, full-field displacements have been obtained at the opposite surface using threedimensional (3D) digital image correlation (DIC) on images obtained through a stereo-vision system (Figure 4). Note that Figure 4 also recalls the presence

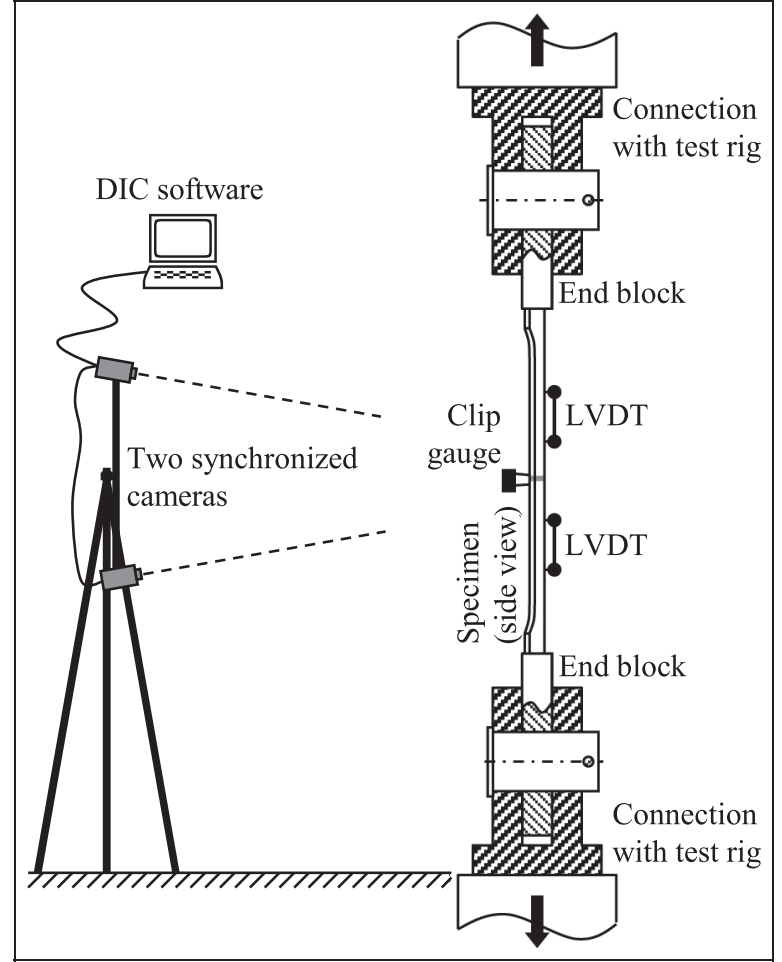

Figure 4. Experimental setup used for the (C)WP tests. DIC: digital image correlation; LVDT: linear variable differential transformer.

of a clip gauge which traverses the flaw. Results obtained with this clip gauge are not further investigated in this paper.

In brief terms, DIC aims to obtain the displacement field that yields the best correlation between the image of a deformed surface and a reference image of the undeformed surface. To quantify this correlation, a sum of squared differences (SSD) is calculated for every investigated point, comparing the grey values of a square subset of pixels around the point in the reference image with the same - but transformed by an assumed displacement field - subset in the deformed image. The displacement of that point is then obtained by minimizing this SSD-function. From the obtained displacement field, in-plane strains can be obtained by means of differentiation.

A proper DIC analysis requires images with a nonuniform high-contrast speckle pattern. This pattern was achieved by spraying a uniform white layer of paint and, after drying, projecting black paint droplets upon the specimen surface. The procedure was optimized to aim for a speckle size of approximately 3 by 3 pixels as advised by Sutton et al. ${ }^{28}$ This roughly corresponds with speckles of $0.8 \mathrm{~mm}$ by $0.8 \mathrm{~mm}$. A subset size of 21 by 21 pixels for calculating the SSD-functions was chosen, aiming to roughly capture three speckles per subset as also advised by Sutton et al. ${ }^{28}$ (Figure 5).

The images were obtained from a stand-alone system provided by Limess Messtechnik \& Software $\mathrm{GmbH},{ }^{29}$ containing two synchronized monochromatic 14 bit cameras with a resolution of 2452 by 2054 pixels 


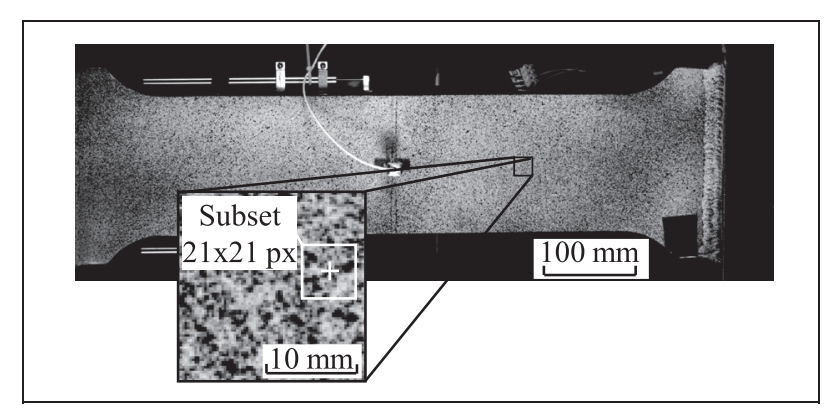

Figure 5. Example speckle pattern applied for the (C)WP tests.

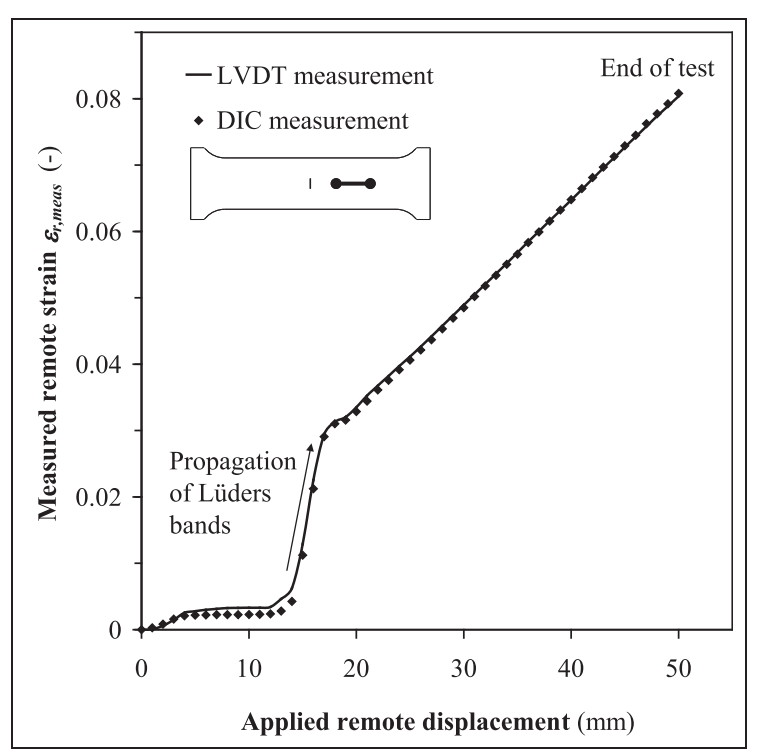

Figure 6. DIC results agree with LVDT measurements (taken from WP2).

DIC: digital image correlation; LVDT: linear variable differential transformer.

(5 megapixels). The use of two cameras allowed to obtain positions and displacements in three dimensions using the VIC3D software of Correlated Solutions Inc. ${ }^{30}$

To gain confidence in the results, the actual LVDT measurements were compared with those of a 'virtual' LVDT measurement at the same location, extracted from the DIC raw data. Figure 6 shows an example comparison and indicates a remarkable correspondence. Since the LVDT and DIC measurements have been obtained at opposite surfaces of the specimen (Figure 4), their agreement indicates that the longitudinal strain distribution - which is the point of interest of this study - is uniform in the through-thickness direction. This justifies the examination of strains over a surface path to represent an entire cross section (see second section).

\section{Finite element study}

Finite element simulations that represent (C)WP tests have been performed by the software package
ABAQUS $^{\circledR}$ (version 6.10). The following paragraphs focus on the general characteristics of the created models (see section 'Structure of the created models') and the simulation matrix (see 'Simulation matrix'). For a more elaborate description of the creation of the models, the reader is referred to Hertele et al. ${ }^{31}$

\section{Structure of the created models}

A Python-script creates models that represent one half of a (C)WP specimen with flawed weld, assuming a longitudinally oriented symmetry plane. The specimen is connected to two rigid end blocks, both of which are impeded to rotate. A tensile deformation is then applied by translating one of the end blocks, keeping the other one fixed in space. From comparison with simulations using elastic end blocks, it has been found that the rigid character of the end blocks does not influence the obtained results.

The finite element models consist of 3D solid linear brick elements with reduced integration (ABAQUS ${ }^{\circledR}$ element type 'C3D8R'). A mesh convergence study ensured that the mesh was sufficiently fine to obtain negligibly small discretization errors. In total, the specimens modelled in the current study contained between 9602 and 17602 elements.

A large-deformation formulation, necessary to obtain realistic deformation patterns in the specimen, has been used for all simulations. Apart from the rigid end blocks, all materials are rate-independent elasticplastic, harden isotropically and obey the Von Mises yield criterion.

Note that residual stresses have not been taken into account for the present study. Two reasons for this simplification can be put forward. First, residual stresses are considered to have an effect on crack driving force rather than remote strain, which is more related to the global geometry and material behaviour. Second, in a strain-based context, residual stresses are often not taken into account because - in contrast with traditional stress-based fracture mechanics - their effect on remote strain capacity has been found fairly limited. It is considered that residual stresses tend to relax under situations of global plasticity. This is reflected in the absence of residual stresses in numerical analyses that led to different existing strain capacity prediction equations, e.g. Kibey et al. ${ }^{2}$ and Østby. ${ }^{32}$

\section{Simulation matrix}

To investigate a range of possible conditions, five parameters have been varied in a simulation matrix. These parameters relate to specimen geometry (diameter-tothickness ratio $\left.D_{o} / t\right)$, material characteristics $\left(O M_{Y S}\right.$, strain-hardening exponent of base and weld metal $n$ ), and relative flaw size $(a / t, 2 c / 2 W)$. The strain-hardening exponent $n$ has been translated into a RambergOsgood model ${ }^{33}$ for true stress-true strain behaviour 
$(\sigma$ : true stress $(\mathrm{MPa}) ; \varepsilon$ : true strain $(-) ; E$ : Young's modulus, taken as 206,900 MPa)

$$
\varepsilon=\frac{\sigma}{E}+0.002\left(\frac{\sigma}{R_{p 0.2}}\right)^{n}
$$

Note that the assumption of the Ramberg-Osgood equation involves an approximation, as a more accurate constitutive law has recently been developed for high-strength pipeline steels. ${ }^{34,35}$ Nevertheless, it has been applied for its simplicity as the main aim of the parametric study was to obtain general trends rather than exact results.

A design-of-experiments (DoE) approach has been applied to reduce the number of simulations required for a statistical analysis. In total, 16 simulations have been performed. For all five varied parameters, realistic 'low' and 'high' values have been chosen (Table 4). Note that the 'high' value of $D_{o} / t$ corresponds with a flat plate. Each simulation is then characterized by a unique combination of 'low' and 'high' values (Table 5). According to DoE theory the simulation matrix has a resolution five, which means that all effects of single parameters and all possible coupled effects can be identified.

Apart from the five varied parameters, all other parameters have been kept fixed for all simulations, notably:

(a) $0.2 \%$ proof stress of base metal $R_{p 0.2 \text {,base: }}$ $500 \mathrm{MPa}$;

(b) weld geometry: root opening $5 \mathrm{~mm}$, bevel angle $10^{\circ}$, no weld cap reinforcement; (c) flaw depth: $3 \mathrm{~mm}$. This is a commonly used value in curved wide plate testing, as it typically corresponds with the height of one girth weld pass.

Additional to the 16 performed simulations, a simulation with all conditions of WP2 has been performed. This simulation aims to validate the accuracy of the finite element model through a comparison with the experimental test result (see section 'Validation of the finite element model').

\section{Results and discussion}

\section{Validation of the finite element model}

To validate the finite element model, the strain distribution of the WP2 simulation has been compared with that of the experiment. On the one hand, the model does not predict the propagation of Lüders bands as experimentally observed in Figure 7(a). This is not surprising, as modelling this phenomenon is known to be highly challenging and requires material input with an adapted Lüders plateau representation. ${ }^{36,37}$ On the other hand, comparison of Figures 7(b) and (c) indicates a strong correspondence between the results of the experiment and the finite element simulation after the Lüders bands have fully developed. Both simulation and experiment show the presence of shear lines originating from the defect and so-called 'strain hotspots' near the specimen shoulders. The presence of these strain hotspots - caused by the restraint of the shoulders when the prismatic specimen section is plastically deformed - is confirmed in Wang et al., ${ }^{10}$ Fairchild et al. ${ }^{11}$ and Hertelé et al. ${ }^{12}$

Table 4. Values given to the five parameters, varied in the parametric study.

\begin{tabular}{|c|c|c|c|}
\hline Parameter & Symbol (dimension) & Low value ('-’) & High value (' +’) \\
\hline Yield strength overmatch & $O M_{Y S}(\%)$ & 0 & 20 \\
\hline Strain hardening exponent & $n(-)$ & 15 & 25 \\
\hline Plate outside diameter/plate thickness & $D_{o} / t(-)$ & $\begin{array}{l}40 \\
\text { (curved plate) }\end{array}$ & $\begin{array}{l}\infty \\
\text { (flat plate) }\end{array}$ \\
\hline Relative flaw depth & $a / t(-)$ & $\begin{array}{l}0.15 \\
(t=20 \mathrm{~mm})\end{array}$ & $\begin{array}{l}0.30 \\
(t=10 \mathrm{~mm})\end{array}$ \\
\hline Relative flaw length & $2 c / 2 W(-)$ & $\begin{array}{l}0.17 \\
(2 c=25 \mathrm{~mm})\end{array}$ & $\begin{array}{l}0.33 \\
(2 c=50 \mathrm{~mm})\end{array}$ \\
\hline
\end{tabular}

Table 5. Simulation matrix.

\begin{tabular}{|c|c|c|c|c|c|c|c|c|c|c|c|c|c|c|c|c|}
\hline \multirow[t]{2}{*}{ Parameter } & \multicolumn{16}{|c|}{ Simulation no. } \\
\hline & $\mathrm{I}$ & 2 & 3 & 4 & 5 & 6 & 7 & 8 & 9 & 10 & 11 & 12 & 13 & 14 & 15 & 16 \\
\hline$O M_{Y S}$ & - & - & - & - & - & - & - & - & + & + & + & + & + & + & + & + \\
\hline$n$ & - & - & - & - & + & + & + & + & - & - & - & - & + & + & + & + \\
\hline$D_{0} / t$ & - & - & + & + & - & - & + & + & - & - & + & + & - & - & + & + \\
\hline$a / t$ & + & - & + & - & + & - & + & - & + & - & + & - & + & - & + & - \\
\hline $2 c / 2 W$ & + & - & - & + & - & + & + & - & - & + & + & - & + & - & - & + \\
\hline
\end{tabular}




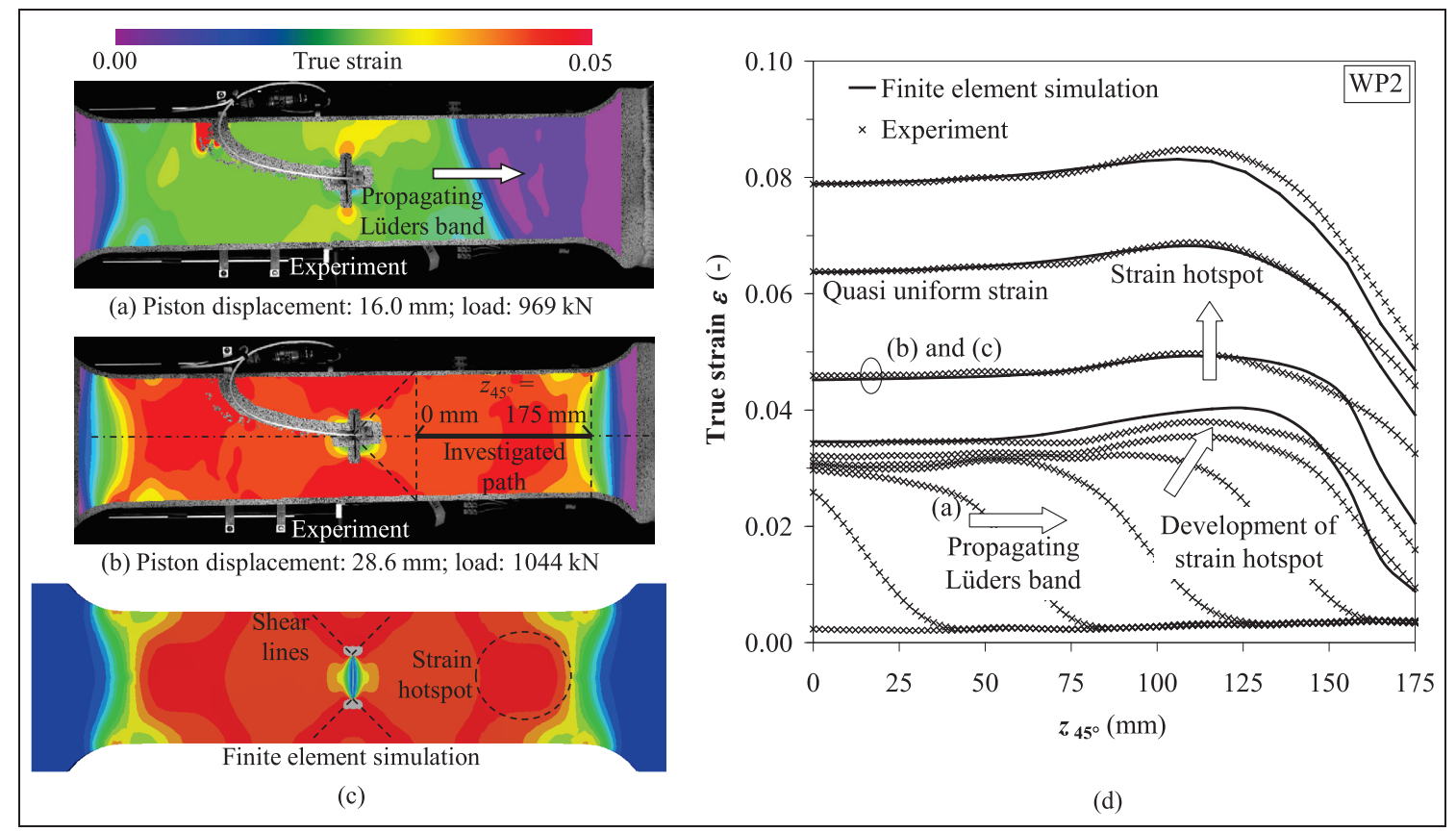

Figure 7. After the development of Lüders bands (a), the longitudinal strain distribution of WP2 is well predicted by finite element analysis ((b) versus (c)). Quantitative results are shown in (d), which also indicates the position of (a), (b) and (c) in this graph.

The abovementioned findings are quantitatively confirmed in Figure 7(d), which plots the distribution of longitudinal strain along the 'investigated path' line shown on the DIC contour plot of Figure 7(b) with each line representing increasing applied displacement. Accepting the unavoidable uncertainties involved with experimenting and the numerical assumptions of finite element analysis, the finite element model satisfactorily describes the strain hotspots after the development of the Lüders bands. Note that the agreement vanishes beyond the strain hotspots, more closely to the shoulders (say, $z_{45^{\circ}}$ $>150 \mathrm{~mm}$ ). Although the exact cause of this observation is not known to the authors, a reason might be the pronounced biaxial stress state near the shoulders. Indeed, the finite element result indicates a biaxiality ratio (transversal stress divided by longitudinal stress) of typically 0.2 in the shoulder area. In such case, effects of anisotropy may not be captured by the finite element model, which assumes isotropical strength properties. Nevertheless, this area is not of particular interest for the presented study and the overall finite element result is considered acceptable.

\section{Uniformity of strain distribution}

As explained in the second section, the uniformity of the strain distribution has been examined on the basis of $\overline{c_{v}}$ in five cross-sections (Figure 2). Figure 8 depicts the results for (a) the 16 simulations summarized in Table 5, and (b) the three experiments WP1, WP2 and WP3. Since the cable of the clip gauge traversing the flaw obstructed the camera view on the left sides of the specimens (see e.g. Figure 7(b)), only the right sides have been analyzed.

For the finite element results, $\overline{c_{v}}$ (equation (1)) has been obtained from integration between zero deformation $\left(\varepsilon_{i}=0\right)$ and failure. For the experimental results, the inherently non-uniform strain distribution during the propagation of Lüders bands has been excluded from the evaluation by modifying $\varepsilon_{i}$ to the Lüders elongation (Table 3). As mentioned in the second section failure has been defined as the moment where necking initiates, i.e. tensile load drops.

On the one hand, the numerical results (Figure 8(a)) predict the following trends.

1. The cross section with the most uniform strain distribution systematically occurs near $z_{45^{\circ}}=$ $50 \mathrm{~mm}$ (or, relative to the specimen dimensions, $z_{45^{\circ}}=2 \mathrm{~W} / 3$ ). The average coefficient of variance observed there is systematically below 0.02 , which indicates a high degree of uniformity. Hence, this location is advisable for strain gauge measurements.

2. The non-uniformity near the strain hotspots $\left(z_{45^{\circ}}=75\right.$ and $\left.100 \mathrm{~mm}\right)$ is mostly determined by the strain hardening behaviour of the base metal (characterized by $n$ and distinguished in Figure 8(a) by means of different marker shapes - circular and triangular). This seems logical, as the evolution of plasticity is known to depend on the stressstrain properties of a material.

3. At a position $z_{45^{\circ}}=0 \mathrm{~mm}$, a large factor of influence seems to be the defect size, relative to the cross section surface. Indeed, Figure 8(a) highlights 


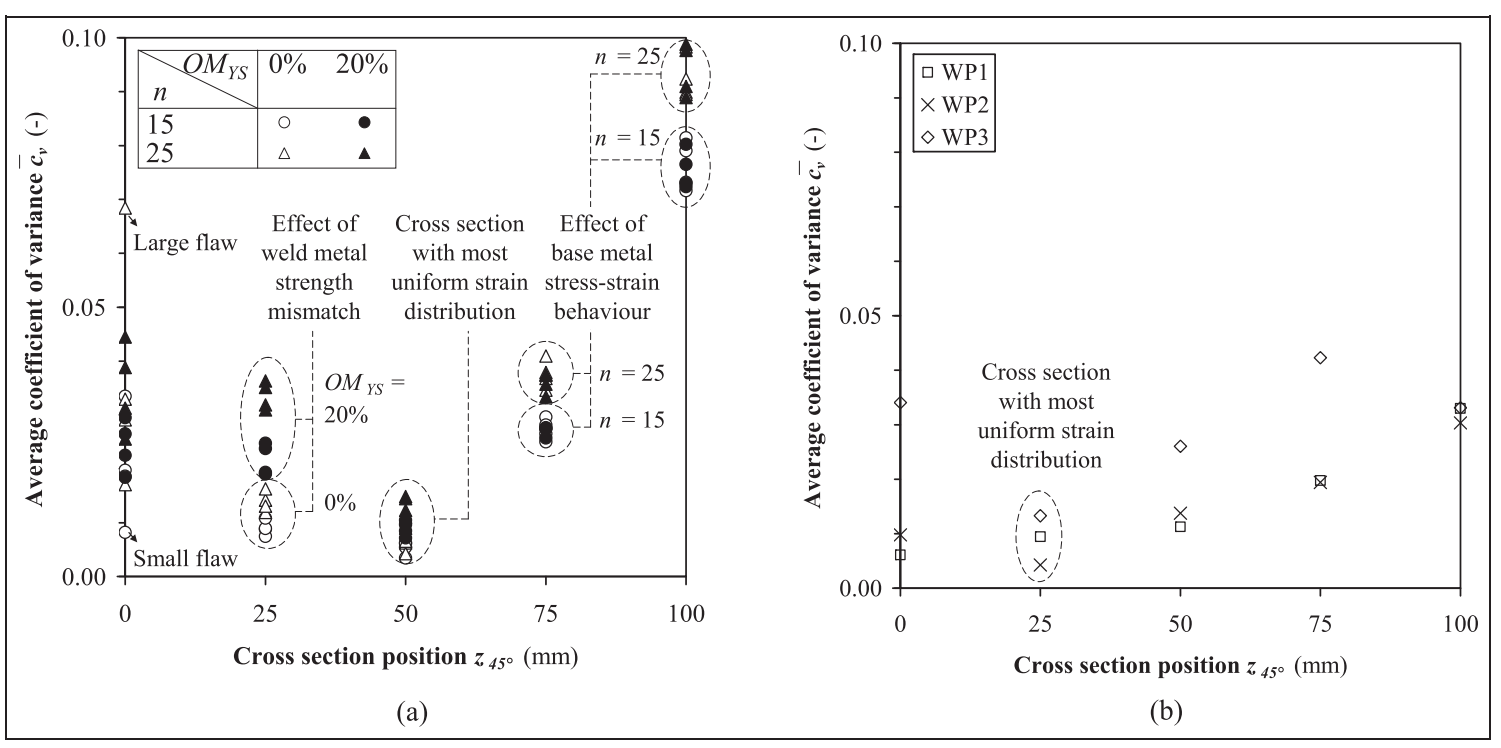

Figure 8. Overview of strain uniformity calculations at five different cross sections: (a) finite element results, (b) experimental results.

a highly non-uniform distribution of strain for a relatively large flaw (simulation $7 ; a / t=0.3$ and $2 c / 2 W=0.33$ ) and a highly uniform distribution for a relatively small flaw (simulation $2 ; a / t=0.15$ and $2 c / 2 W=0.17)$. Note that both simulations are characterized by a situation of zero weld strength overmatch (Table 5). This observation is logical since, in such case, fracture mechanics theoretically predicts shear lines originating from the flaw tip front at angles of approximately $45^{\circ}$ (see also Figure 7(b)). In such case, the strain uniformity at $z_{45^{\circ}}=0 \mathrm{~mm}$ depends on the intensity of those shear lines, which is to a great extent influenced by the flaw dimensions.

4. At $z_{45^{\circ}}=25 \mathrm{~mm}$ all simulations with $O M_{Y S}=$ $20 \%$ (black filled markers) have a higher $\overline{c_{v}}$-value than those with $O M_{Y S}=0 \%$ (unfilled markers), which indicates a local influence of weld strength overmatch.

5. Plate curvature $\left(D_{o} / t\right)$ has not been observed to play a significant role (not shown in Figure 8(a)).

On the other hand, the following has been experimentally observed (Figure 8(b)).

1. WP1 and WP2 behave analogously, which reflects their general similarity (Table 3).

2. In contrast with the finite element simulations, the most uniformly straining cross section is mostly found near $z_{45^{\circ}}=25 \mathrm{~mm}$.

3. The limited number of test results hinders the identification of trends, as was possible with the finite element results. In addition $\overline{c_{v}}$ is influenced by the fact that, in the experiments, the strain distribution is not perfectly symmetrical in the transverse direction (see e.g. Figure 7(b)).
4. The order of magnitude of $\overline{c_{v}}$ is in agreement with the simulations. In particular, the minimum observed $\overline{c_{v}}$-values are also below 0.02 . In general, the area between $z_{45^{\circ}}=25 \mathrm{~mm}$ and $50 \mathrm{~mm}$ (or, in parametric terms, $W / 3$ and $2 W / 3$ ) strains highly uniformly.

5. Although not clearly reflected in Figure 8(b), the experiments confirm the observation from finite element analysis that weld strength mismatch has an influence on the strain distribution in the specimen body. For instance, Figure 9(a) compares the longitudinal strain distributions of WP2 (no weld, copy of Figure 7(b)) and WP3 (strength overmatching weld). Whereas WP2 shows pronounced strain hotspots near the shoulder, WP3 has a larger zone of strain concentration closer to the flaw section. This is the consequence of the lateral restraint of the stronger weld (Poisson effect), which changes the hydrostatic component of the stress tensor in the plate. The restraint effects are reflected in the transversal strain distributions, which fundamentally differ between WP2 and WP3 (Figure 9(b)).

6. Apart from the discussion above, also note that the left plate of WP3 strains significantly less than the right plate (Figure 9(a)), which is the consequence of their heterogeneous strength properties (Table 3).

The differences observed between experiments and simulations may be attributed to different potential causes, notably: different yielding behaviours (all simulations assumed continuously hardening materials, whereas all experiments showed materials with a Lüders plateau), the absence of heterogeneity between both sides of the specimen in the simulation (which is 


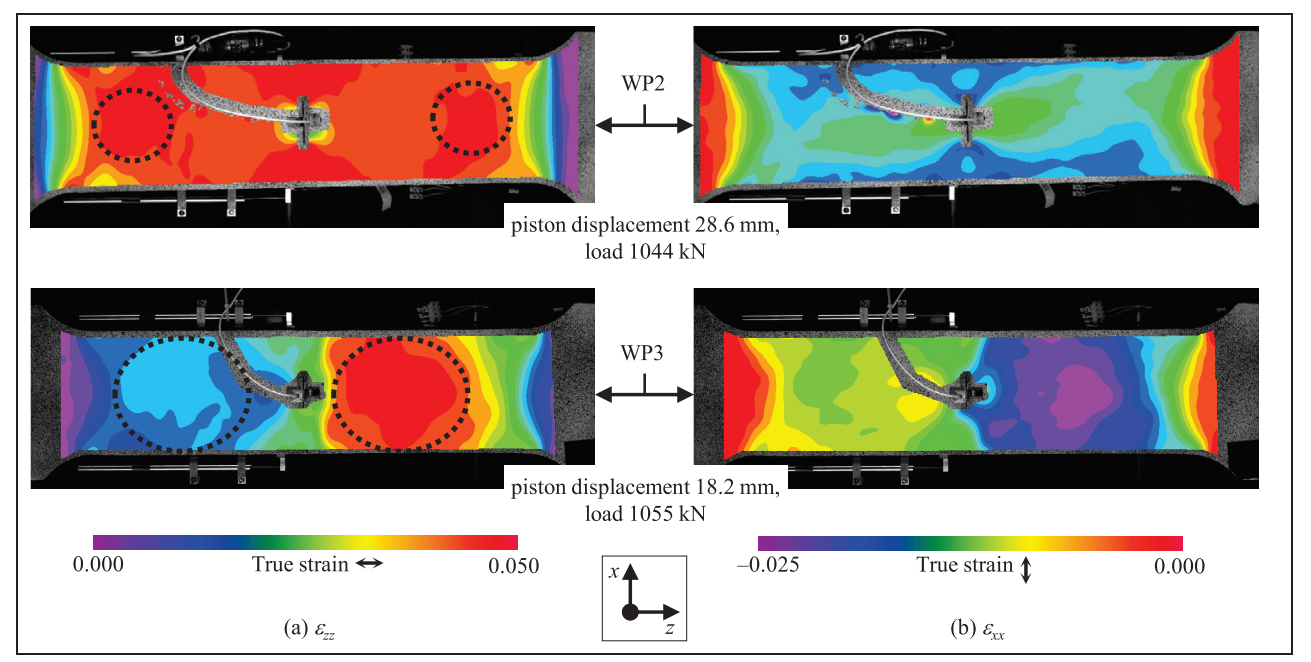

Figure 9. Weld strength overmatch has an influence on transversal restraint (b) and, as a consequence, on the longitudinal strain distribution (a).

pronounced in the experiment WP3), and/or the assumption of isotropical yielding behaviour in the simulations. As such, the differences between Figure 8(a) and Figure 8(b) should not be seen as a poor agreement between simulations (which have been validated in the fifth section under 'Validation of the finite element model') and experiments.

Finally it can be noted that, for both simulations and experiments, shear strains have been found negligible with respect to the longitudinal strain level in the zones of optimal uniformity.

\section{Remote strain measurements}

As discussed in the second section, both strain gauges and LVDTs are considered for measurements of remote strain. First, if strain gauges are applied, it is advised to place them in an area of highly uniform longitudinal strain. From the fifth section under 'Uniformity of strain distribution', the area $W / 3<z_{45^{\circ}}<2 W / 3$ can be advised. Given the natural scatter observed in the experimental strain distributions (see e.g. Figure 9(a)) and the local character of a strain gauge measurement, it seems appropriate to place multiple strain gauges and average their outcome.

Second, to evaluate the representativeness of the four LVDT measurements considered in Figure 2, Figures 10 (a) to (d) depict the evolution of $\varepsilon_{r, \text { meas }} / \varepsilon_{r, \text { ref }}$ for the experiments and a selection of simulations. From section 5.2, $O M_{Y S}$ and $n$ have been identified as the key influences for the strain distribution. Hence, four simulations have been selected from Table 5 including all possible combinations between $O M_{Y S}$ and $n$ (simulations 1, 7, 11 and 13). The other twelve simulations perform similarly. Further, the simulation of WP2 has been included for comparison with its experimental equivalent. The following is observed.
1. Apart from the LVDT with gauge length $150 \mathrm{~mm}$ (Figure 10(d)), there is a good qualitative correspondence between the experiment WP2 and its validation simulation. This results from the agreement between their strain distributions (Figure 7),

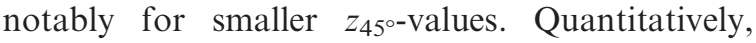
their results differ by approximately $1 \%$ in Figures 10 (a) to (c), which is acceptable.

2. The four selected simulations from the parametric study indicate that, apart from the measurement with gauge length $100 \mathrm{~mm}$, there is a significant influence of $n$, and an influence of $O M_{Y S}$ which vanishes for larger gauge lengths.

3. As in Figure 8(b), WP1 and WP2 behave similarly which adds confidence to the outcome of the experiments.

4. Considering all simulations and experiments, the LVDT with gauge length $100 \mathrm{~mm}$ (Figure 10(b)) is the only one that systematically produces measurements which are in close agreement with the reference strain for the entire course of the (curved) wide plate test. The observed strain measurement mostly does not exceed the reference strain by more than $2 \%$. In general terms, the $100 \mathrm{~mm}$ long LVDT is characterized by endpoints which are located at a distance $W$ from the flawed section and from the shoulder onset, respectively. It can be noted that similar LVDT endpoint positions have been advised in Denys and Lefevre ${ }^{22}$ for wide plates with a $L / W$ ratio 3 .

5. Although the $100 \mathrm{~mm}$ long LVDT is clearly advisable, LVDT measurements generally seem to be fairly insensitive to gauge length variations. Indeed, the divergence between measured strain and reference remote strain does not exceed 5\% for the LVDTs with gauge lengths $75 \mathrm{~mm}(W)$ and $125 \mathrm{~mm}(5 \mathrm{~W} / 3)$. 


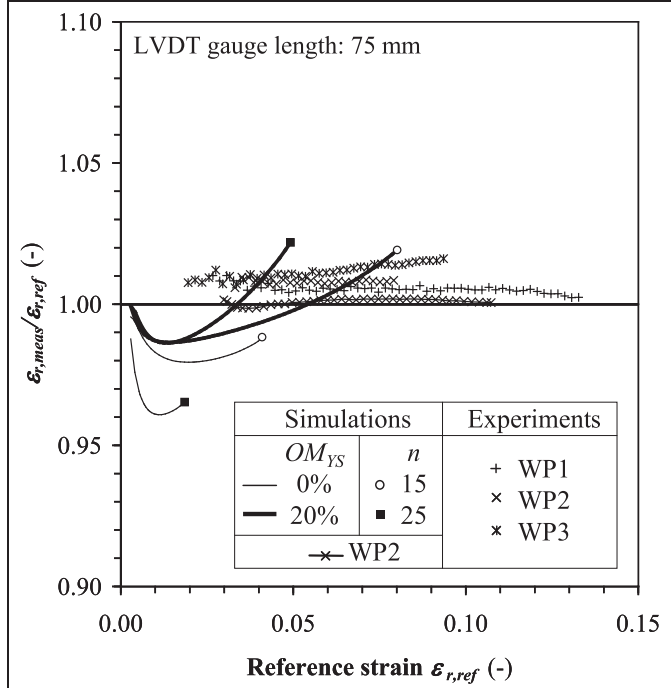

(a)

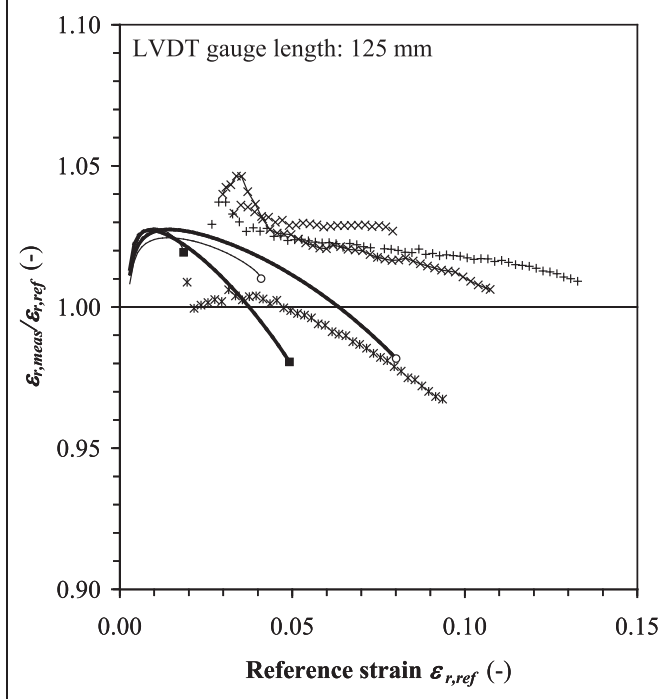

(c)

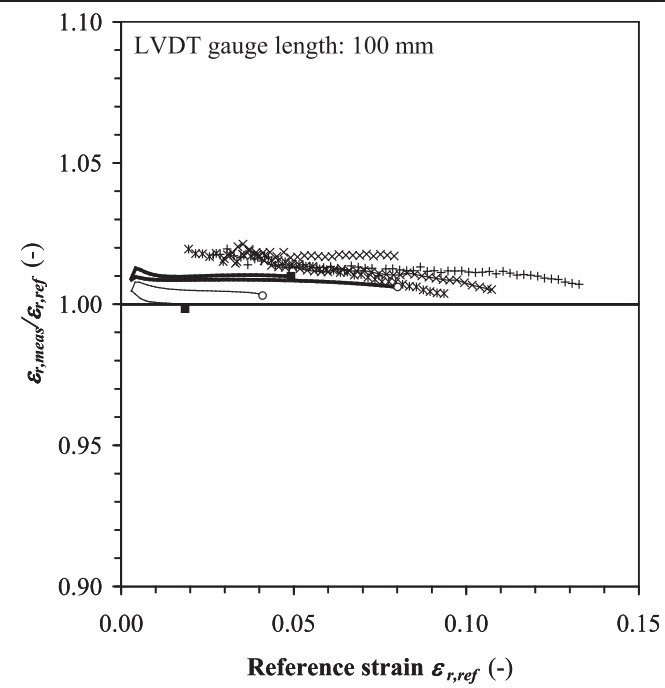

(b)

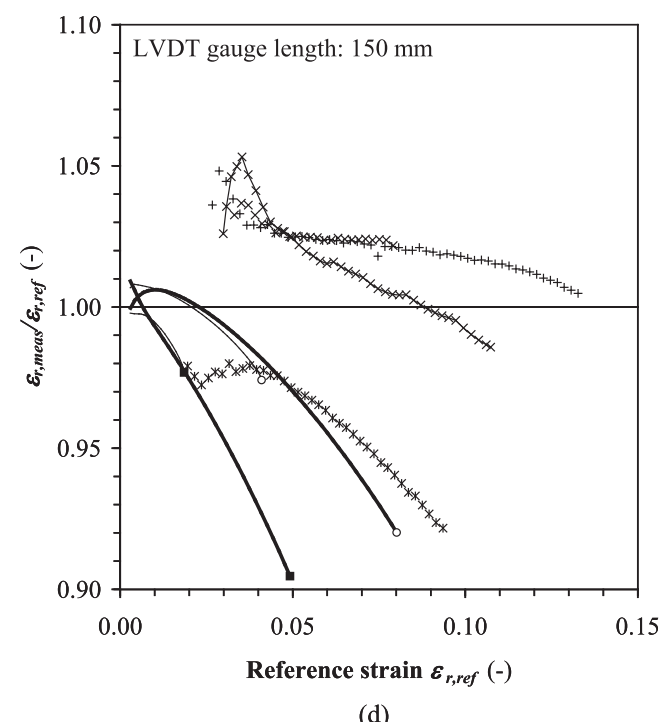

(d)

Figure 10. Overview of remote strain calculations by LVDT measurements: experimental results and a selection of finite element simulation results.

LVDT: linear variable differential transformer.

\section{Conclusions}

Different remote strain measurements have been investigated for a (curved) wide plate tension specimen characterized by a length-to-width ratio of 3.33 . This ratio is larger than 3 which is, according to literature, desirable to obtain a zone of uniform longitudinal strain and to avoid an influence of the specimen end shoulders on the test result.

The investigation has been performed on the basis of three experiments with digital image correlation (DIC) strain measurements and a parametric study using an experimentally validated finite element model. The following conclusions can be drawn.

1. The strain distribution at each side of the flawed section is generally characterized by a strain hotspot whose size, position and intensity is mostly determined by the strain hardening behaviour of the base metal and the strength mismatch of the weld (if present).

2. Despite the presence of strain hotspots, a considerable area of approximately uniform longitudinal strain is obtained. Hence, the highly non-uniform strain distribution near the end shoulders is not extended towards the flawed section.

3. If strain gauges are used to obtain remote strain, placing them between $4 W / 3$ and $5 W / 3$ away from the flawed section yields representative measurements ( $2 W$ being the specimen width). Given the local nature of a strain gauge measurement and the unavoidable presence of a slightly scattered strain distribution, it is advised to place multiple strain gauges and average their outcome.

4. If LVDTs are used to obtain remote strain, the presented study proposes to place one endpoint at 
a distance $W$ from the flawed section. In that case, gauge lengths between $W$ and $5 W / 3$ are advised, the optimum value being $4 W / 3$. Such LVDT is in accordance with the configuration advised in Denys and Lefevre ${ }^{22}$ for a (curved) wide plate specimen with a length-to-width ratio 3 .

\section{Funding}

This work was supported by the FWO - Vlaanderen (Research Foundation - Flanders) [grant numbers 1.1.880.09.N.00, 1.1.880.11.N.01, 1.5.247.08.N.00] and the IWT Vlaanderen (Government Agency for Innovation by Science and Technology) [grant numbers SB-091512 and SB-093512].

\section{Acknowledgements}

Special thanks go to Frederik Van Acker, Karel De Keyser and the academic and technical staff of Laboratory Soete for their unmistakable contributions to the successful execution of the reported wide plate tests, and to Ralf Lichtenberger for his technical support with regard to the DIC system.

\section{References}

1. Østby E, Thaulow C and Nyhus B. A new approach to ductile tearing assessment of pipelines under large-scale yielding. Int J Press Vessels Pip 2007; 84(6): 337-348.

2. Kibey S, Wang X, Minnaar K, et al. Tensile strain capacity equations for strain-based design of welded pipelines. In: Proceedings of the 8th ASME international pipeline conference, Calgary, Alberta, Canada, 27 September-1 October 2010, paper IPC2010-31661.

3. Roop WP. Notes on the conditions of brittle rupture of ship plates of medium steel. TMB Report R-276, US Navy, Washington DC, 1944.

4. Cravero S, Bravo RE and Ernst HA. Constraint evaluation and effect on $\mathrm{J}-\mathrm{R}$ resistance curves for pipes under combined load conditions. In: Proceedings of the 18th ISOPE international offshore and polar engineering conference, Vancouver, Canada, 6-11 July 2008, pp.149-156.

5. Cravero S, Bravo RE and Ernst HA. Fracture evaluation of cracked pipelines subjected to combined loading. In: Proceedings of the 5th international conference on pipeline technology, Ostend, Belgium, 12-14 October 2009.

6. Wang YY, Liu M, Weeks T, et al. Broad perspectives of girth weld tensile strain response. In: Proceedings of the 8th ASME international pipeline conference, Calgary, Alberta, Canada, 27 September-1 October 2010, paper IPC2010-31369.

7. De Keyser K, Van Acker F, Hertelé S, et al. Validation of a wide plate finite element model using digital image correlation. Sustain Constr Des 2011; 2: 416-423.

8 Helm JD Sutton MA and McNeill SR. Deformations in wide, center-notched, thin panels, part I: threedimensional shape and deformation measurements by computer vision. Opt Eng 2003; 42(5): 1293-1305.

9. Helm JD, Sutton MA and McNeill SR. Deformations in wide, center-notched, thin panels, part II: finite element analysis and comparison to experimental measurements. Opt Eng 2003; 42(5): 1306-1320.

10. Wang YY, Liu M, Chen Y, et al. Effects of geometry, temperature, and test procedure on reported failure strains from simulated wide plate tests. In: Proceedings of the 6th ASME international pipeline conference, Calgary, Alberta, Canada, 25-29 September 2006, paper IPC200610497.

11. Fairchild DP, Cheng W, Ford SJ, et al. Recent advances in curved wide plate testing and implications for strainbased design. Int J Offshore Polar Eng 2008; 18(3): 161-170.

12. Hertelé S, De Waele W, Denys R, et al. Investigation of pipe strain measurements in a curved wide plate specimen. In: Proceedings of the 8th ASME international pipeline conference, Calgary, Alberta, Canada, 27 September-1 October 2010, paper IPC2010-31292.

13. ASTM E 740-03(2010). Standard practice for fracture testing with surface-crack tension specimens. ASTM International, West Conshohocken, USA, 2010.

14. Minami F, Ohata M, Toyoda M, et al. The effect of weld metal yield strength on the fracture behaviour of girth welds in grade 550 pipe. In: Proceedings of pipeline technology, Ostend, Belgium, 11-14 September 1995, 1, pp.441-461.

15. Minami F, Takashima $Y$ and Ohata M. Constraint-based assessment of CTOD toughness requirement for high-strain line pipe. Int J Offshore Polar Eng 2011; 21(2): 129-140.

16. Motarjemi A. Strain-based engineering critical assessment (ECA) of partially mismatched girth welds. In: Proceedings of the 5th international conference on pipeline technology, Ostend, Belgium, 12-14 October 2009.

17. Ishikawa R, Endo S, Igi S, et al. Ductile fracture behaviour of girth-welded joints and strain-based design for high-strength pipeline. In: Proceedings of the 4th international conference on pipeline technology, Ostend, Belgium, 9-13 May 2004, 1, pp.81-98.

18. Igi S and Suzuki N. Tensile strain limits of $\mathrm{X} 80$ high-strain pipelines. In: Proceedings of the 17th ISOPE international offshore and polar engineering conference, Lisbon, Portugal, 1-6 July 2007, pp.3081-3087.

19. Denys R. Wide plate testing of weldments, Part II Wide-plate evaluation of notch toughness. In: ASTM STP 1058 - fatigue and fracture testing of weldments, 1990, pp.157-228.

20. Igi S, Sakimoto T, Suzuki N, et al. Tensile strain capacity of X80 under tensile loading with internal pressure. In: Proceedings of the 8th ASME international pipeline conference, Calgary, Alberta, Canada, 27 September-1 October 2010, paper IPC2010-31281.

21. Igi S, Sadasue T, Kubo T, et al. Effect of crack geometry and tensile properties on tensile strain limit of X80 linepipe. In: Proceedings of the 18th ISOPE international offshore and polar engineering conference, Vancouver, BC, Canada, 6-11 July 2008, pp.79-85.

22. Denys R and Lefevre A. UGent guidelines for curved wide plate testing. In: Proceedings of the 5th international conference on pipeline technology, Ostend, Belgium, 12-14 October 2009.

23. Richards M, Weeks T, McColskey D, et al. Fatigue precracking curved wide plates in bending. In: Proceedings of the 8th ASME international pipeline conference, Calgary, Alberta, Canada, 27 September-1 October 2010, paper IPC2010-31468. 
24. Stephens MJ, Randy T, Petersen RT, et al. An experimental basis for improved strain-based design models. In: Proceedings of the 19th ISOPE international offshore and polar engineering conference, Osaka, Japan, 21-26 June 2009, pp.29-35.

25. Stephens M, Petersen R, Wang YY, et al. Large scale experimental data for improved strain-based design models. In: Proceedings of the 8th ASME international pipeline conference, Calgary, Alberta, Canada, 27 September-1 October 2010, paper IPC2010-31396.

26. Bannister AC, Ocejo JR and Gutierrez-Solana F. Implications of the yield stress/tensile stress ratio to the SINTAP failure assessment diagrams for homogeneous materials. Eng Fract Mech 2000; 67(6): 547-562.

27. Dallam C, Huysmans S, Denys R, et al. Design criteria for X80 pipe welding: process and strength effects on weld performance in wide plate tests. In: Proceedings of the 5th international conference on pipeline technology, Ostend, Belgium, 12-14 October 2009.

28. Sutton MA, Orteu, JJ and Schreier HW. Image correlation for shape, motion and deformation measurements. Basic concepts, theory and application. Springer, 2009.

29. Limess Messtechnik \& Software GmbH, www.limess.com (accessed 20 February 2012).

30. Correlated Solutions Inc. (2011) www.correlatedsolutions. com. (accessed 20 February 2012.

31. Hertelé S, De Waele W, Denys R, et al. Parametric finite element model for large scale tension tests on flawed pipeline girth welds. Adv Eng Software 2012; 47(1): 24-34.

32. Østby E. Fracture control - offshore pipelines - new strain-based fracture mechanics equations including the effects of biaxial loading, mismatch and misalignment. In: Proceedings of the 24th ASME international conference on offshore mechanics and arctic engineering, Halkidiki, Greece, 12-17 June 2005, paper OMAE2005-67518.

33. Ramberg W and Osgood WR. Description of stress-strain curves by three parameters. National Advisory Committee for Aeronautics, Technical note No. 902, 1943.

34. Hertelé S, De Waele W and Denys R. A generic stressstrain model for metallic materials with two-stage strain hardening behaviour. Int J Non-Lin Mech 2011; 46(3): $519-531$.
35. Hertelé S, De Waele W and Denys R. Full-range stressstrain behaviour of contemporary pipeline steels: Part I. Model description. Int J Press Vessels Pip 2012; 92: 34-40.

36. Beissel S and Belytschko T. On patterns of deformation in phase transformations and Lüders bands. Int $J$ Solids Struct 1996; 33(12): 1689-1707.

37. Kyriakides $\mathrm{S}$ and Miller JE. On the propagation of Lüders bands in steel strips. J Appl Mech Trans ASME 2000; 67(4): 645-654.

\section{Appendix}

\section{Notation}

$a \quad$ flaw depth (mm)

$c \quad$ half of flaw length (mm)

$c_{v} \quad$ strain coefficient of variance (-)

$D_{o} \quad$ pipe outside diameter $(\mathrm{mm})$

$E \quad$ Young's modulus (MPa)

$G L_{0} \quad$ initial LVDT gauge length (mm)

$L \quad$ half of prismatic specimen length ( $\mathrm{mm})$

$L / W \quad$ specimen length-to-width ratio $(-)$

$L_{s} \quad$ shoulder runout length (mm)

$L_{t o t} \quad$ half of total specimen length ( $\left.\mathrm{mm}\right)$

$n \quad$ strain hardening exponent $(-)$

$O M_{Y S} \quad$ weld yield strength overmatch $(\%)$

$t \quad$ wall thickness ( $\mathrm{mm})$

$R_{m} \quad$ ultimate tensile strength $(\mathrm{MPa})$

$R_{p 0.2} \quad 0.2 \%$ proof stress (MPa)

$R_{s} \quad$ shoulder radius (mm)

$W \quad$ half of prismatic specimen width (mm)

$W_{\text {tot }} \quad$ half of total specimen width (mm)

$\varepsilon \quad$ (average) logarithmic strain (-)

$\varepsilon_{r, \text { meas }} \quad$ measured remote strain $(-)$

$\varepsilon_{r, \text { ref }} \quad$ reference remote strain (-)

$\sigma \quad$ true stress (MPa)

$\Delta G L \quad$ LVDT gauge length extension (mm) 